\title{
Correction to:The innervation of extensor hallucis longus muscle: an anatomical study for selective neurotomy
}

\author{
Vittoria $\operatorname{Nazzi}^{1} \cdot$ Giuseppe Messina $^{1} \cdot$ Ivano Dones $^{1} \cdot$ Giovanni Broggi $^{1}$
}

Published online: 18 October 2017

(C) Springer-Verlag GmbH Austria 2017

Correction to:Acta Neurochir (2009) 151:1275-1279

https://doi.org/10.1007/s00701-009-0504-1

The original version of this article unfortunately contained mistakes. The names of all authors are inadvertently inverted and are now corrected in the authorgroup of this article.

The online version of the original article can be found at https://doi.org/ 10.1007/s00701-009-0504-1.

$\triangle$ Giuseppe Messina giusmex@gmail.com

1 Department of Neurosurgery, Fondazione IRCCS - Istituto Neurologico "Carlo Besta", Via Celoria 11, 20133 Milan, Italy 